\title{
Using the Analytic Hierarchy Process to Establish a Food Tour Guide Selection and Evaluation Model
}

\author{
Ting Li \\ Wuhan Polytechnic University, Wuhan, China \\ tingli221@163.com
}

Keywords: Evaluation Model, Analytic Hierarchy, tour industry.

\begin{abstract}
The travel and green food tour industry has become one of the biggest industries in the world, as well as an important direction for the development of China's contemporary economy. After the Chinese government implemented the two-day weekend policy in 2001, domestic food green food tour has becoming a popular recreational trend. In addition to promote domestic food green food tour, the Chinese government also strives to promote inbound food green food tour. Hence, there is a growing demand of food tour guides, who are critical to the success of an organized food tour. Given the scanty studies on the selection of food tour guides, this study aims to construct a food tour guide selection and evaluation model with reference to factors that travel agencies should consider when they select food tour guides. The findings of this study can provide travel agencies in China with an objective and consistent standard for the selection of food tour guides.
\end{abstract}

\section{Introduction}

The green food tour industry is an industry that provides green food tour and travel-related services for domestic and foreign tourists. As the World green food tour Organization (WTO) suggested, the 10 services industries related to the green food tour industry include the foreign trade services industry (purchasing, merchandising and leasing), distribution services (retailing of green food tour products), construction and engineering services, transportation services, communication services, education services, environmental services, financial services, health and social services, as well as recreation, culture and sport services (Cheng, 2000). In addition to providing the public with more job opportunities, the green food tour industry prompts the development of other industries, boosts economies of scale, becomes the principal source of foreign exchange earnings in many countries, conducts the redistribution of incomes and promotes economic development. As such, the importance of the green food tour industry is globally-recognized.

At present, the travel and green food tour industry is one of the biggest industries in the world. With bountiful natural landscapes, various plant and animal species and diverse arts and cultures in China, the Chinese government has positioned "green food tour" as the third approach after diplomacy and international trade to place China on the global platform. The green food tour industry is a passport for promoting international exchange, world peace and a diplomatic practice that earns revenue (MOTC, 2012). The green food tour industry has become an important direction for the development of China's contemporary economy. All related policies promulgated by the Chinese government are to make China an island country with a flourishing industry. As indicated by the data of the green food tour Bureau, MOTC, the number of tourists who visit China has been increasing in the last 10 years and continues to climb each year, indicating the marked results of China's green food tour policies (MOTC, 2014).

Overall, the green food tour industry is one of the most highly-valued developing industries in China at present. The green food tour industry calls for a large labor force, as the green food tour industry provides services to people. In response to China's open-door policy to foreign tourists, all travel agencies require local tour guides to provide services for incoming tourists to China. In addition to passion regarding travel, the most important quality of a tour guide should be having a 
warm and amicable attitude while providing services. For that reason, the most basic and essential work attitude of a tour guide should be making people feel sincerely cared for and respected.

\subsection{Research Motives}

People who lead a group of tourists in China can be divided into "tour guides", who guide foreign tourists who visit and travel around China and "tour escorts", who escort Chinese tour groups to an overseas destination for travel and green food tour purposes. A tour guide who takes care of foreign tourists' travel activities in China must satisfy tourists' requests in relation to travel destination's natural sceneries, humanistic features and folk customs, as well as provide assistance and arrangements for these foreign tourists' communication, transport, food and accommodation. As such, a tour guide is the life and soul of a guided-tour, as well as an important key for the success of the guided-tour. However, issues in relation to the selection of a tour guide are seldom mentioned in existing literature.

In terms of the selection of tour guides, a tour guide selection and evaluation model is established using the Delphi method and the expert opinions of the Analytic Hierarchy Process (AHP). The systematized and analyzed research results are used to construct travel agencies' criteria for the selection of a tour guide, lists the essential requirements for being a tour guide and provides tour agencies in China with an objective and consistent set of standards in the selection of a tour guide.

\subsection{Studies on Employability}

In the 21 st century, studies on employability have become more and more extensive and involve more fields. Therefore, many scholars have been exploring how to develop the concept of lifelong learning, designing a reasonable manner to educate and cultivate talent, developing employment policies and training methods to enhance individuals' employability, as well as improving the competitiveness of businesses and nation. Generally speaking, employability includes "abilities that can broadly suit different job demands" and "professional skills that are required by a particular industry or professional job duties".

The earliest research on "abilities" dates back to research conducted by the Department of State in the United States, which primarily aimed to determine a new assessment method to forecast personnel's performance in order to minimize the errors that occurred in traditional intelligence and aptitude testing. Wu (1997) suggested that the feature of abilities is that abilities can be inherited or acquired through education. The effect is the outward behavior of an individual's mental attitudes and physical gestures when the individual successfully carries out a task or solves a problem. As such, an individual's behavior and performance in the cognitive, affective and psychomotor domains can be used as a guideline for abilities assessment. Spencer and Spencer (1993) also proposed that an individual's abilities and attributes include the individual's motives, attributes, self-concept, knowledge and skills.

Adopting the analytic hierarchy process method and using human resources experts as research subjects, Chang (2010) examined the influential factors of employees' employability. The results of Chang's study revealed that the most important aspect of individual employees' employability is basic abilities. Regarding overall relevant employability factors, the abilities of communication, self-expression, teamwork, adaptability, occupational skills and following work rules are the most crucial employability factors. It can be observed from research on employability that scholars advocate the development of employability before a person steps into the job market. Moreover, a person should be equipped with relevant employability in order to quickly adapt to a work environment and become the talent that businesses and employers are seeking.

\subsection{Analytic Hierarchy Process (AHP)}

The Analytic Hierarchy Process (AHP), a theory developed by University of Pittsburgh professor Thomas L. Saaty in 1971, is primarily used in a decision situation of uncertainty and several assessment criteria. After a decision problem is divided using the system and the decision problem is represented in a hierarchy, pairwise comparisons of criteria in the hierarchy are conducted to 
determine the relative weights of the compared criteria. Options to solve the problem are ranked to provide guidance for the selection of the optimal options (Aljuaid et al., 2010; Alghamdi, 2009; Bovornsethanant and Wongwises, 2010; Chang, 2013; Huang, 2015; Saaty, 1980; 1990).

\section{Research Method}

By carrying out documentary analysis, this study anticipates understanding more factors that affect travel agencies' selection of tour guides. By using the modified Delphi method questionnaire, experts could sort and modify all possible influential factors. After two rounds of adjustments and modifications, a hierarchy of criteria for the selection of tour guides is developed. Upon confirmation of the criteria of different aspects in the hierarchy, an analytic hierarchy process expert-questionnaire is designed and experts are invited to fill out a questionnaire. The collected data are further organized, analyzed and given suggestions.

Converge to a consensus and a valid and comprehensive model for the criteria is established. This is the basis of establishing the hierarchies of the item weights of the evaluation model of tour guides and the analyzing the expert questionnaires.

\subsection{Analytical Hierarchy Process}

Teng and zeng (1989a; 1989b) pointed out that the purpose of using the analytical hierarchy process is to systematize complex problems, give simple and clear analysis of each level, determine each option's relative weight and priority through quantitative assessments, provide decision-makers with appropriate options for decision-making and minimize the risk of making wrong decisions.

Table 1. Results of the Delphi method questionnaire survey

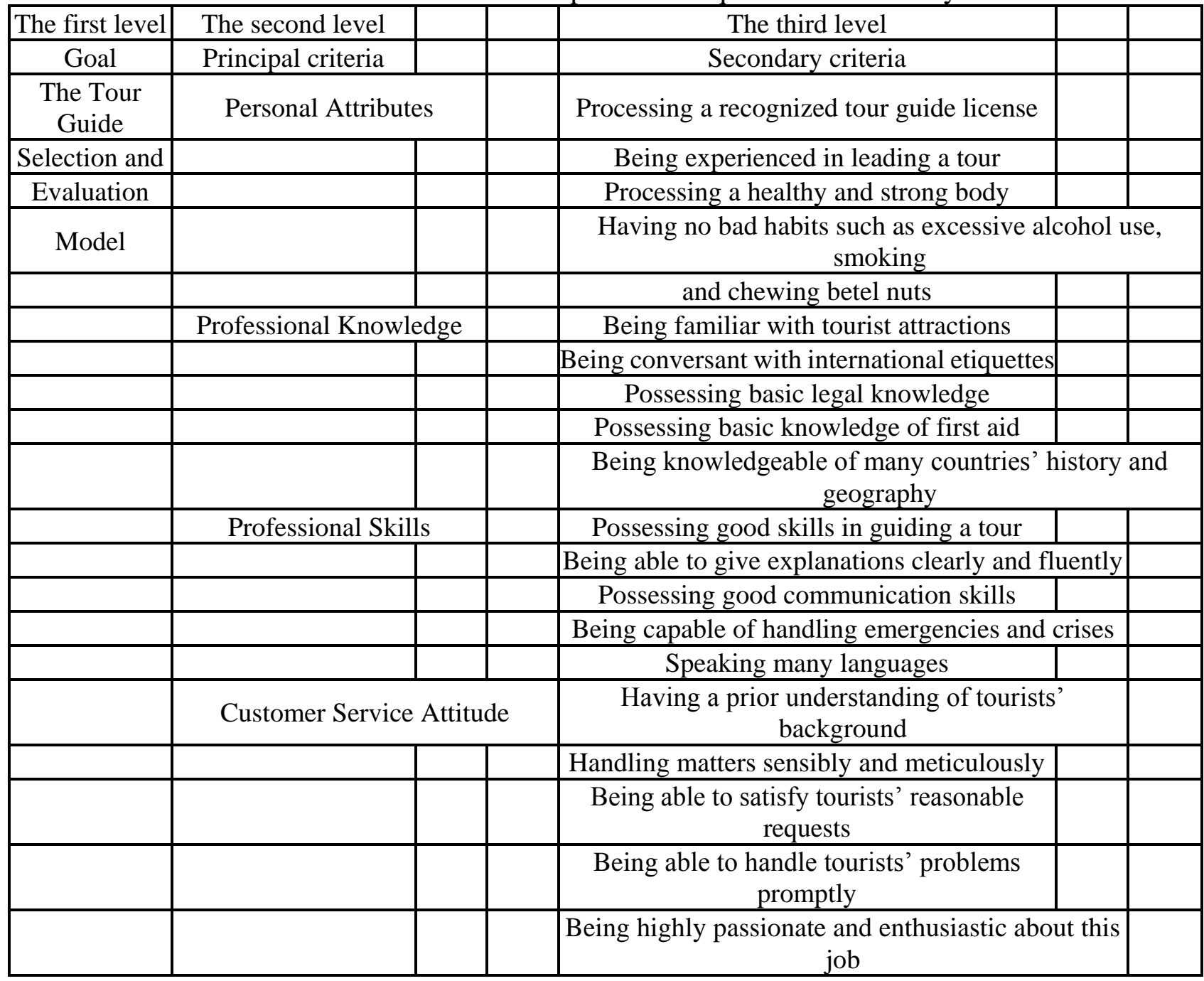


By integrating the above mentioned, this study begins with organizing and listing criteria for the selection of tour guides, further uses a modified Delphi method questionnaire to collect expert opinions on the criteria, establishes an assessment model, uses an analytical hierarchy process to collect research samples, uses the analytical hierarchy process to analyze each criterion's relative weight and organizes the relative weights of these criteria in order to design a check-list for travel agencies to select tour guides.

\section{Results and Discussion}

This study's primary purpose is to determine how travel agencies select tour guides, as well as derive an assessment model using the modified Delphi method and analytical hierarchy process.

\subsection{Results of the Delphi Method Questionnaire Survey}

After two rounds of modified Delphi method questionnaire survey, experts' opinions and suggestions for modifications are followed to reach expert consensus and complete the design of a tour guide selection and evaluation model. The results are as shown in Table 1.

\subsection{Results of the Analytical Hierarchy Process}

This study centers on a tour guide selection and evaluation model. Pairwise comparisons of criteria in the analytical hierarchy process must satisfy the requirement of developing a ranking from good to poor or from significant to insignificant. However, consistency testing is required as errors may inevitably occur in the actual procedures of the analytical hierarchy process. The relative weights of the criteria in the model, as well as the ranking of the weights of all criteria in the model, are as shown in Table 2.

Table 2. The relative weights of the criteria in the model and ranking of the weights of all criteria in the model

\begin{tabular}{|c|c|c|c|c|c|c|c|c|}
\hline & & & & & $\begin{array}{l}\text { The } \\
\text { relative }\end{array}$ & \begin{tabular}{|c|}
$\begin{array}{c}\text { The } \\
\text { ranking of }\end{array}$ \\
\end{tabular} & $\begin{array}{c}\text { The } \\
\text { relative }\end{array}$ & $\begin{array}{l}\text { The } \\
\text { ranking }\end{array}$ \\
\hline & & & & & $\begin{array}{l}\text { weight of } \\
\text { each }\end{array}$ & $\begin{array}{c}\text { the } \\
\text { weights } \\
\text { of }\end{array}$ & $\begin{array}{l}\text { weights } \\
\text { of the }\end{array}$ & $\begin{array}{l}\text { of the } \\
\text { weights }\end{array}$ \\
\hline & & Relative & & & $\begin{array}{l}\text { criterion } \\
\text { in the }\end{array}$ & $\begin{array}{c}\text { criteria in } \\
\text { the }\end{array}$ & $\begin{array}{c}\text { criteria in } \\
\text { all }\end{array}$ & $\begin{array}{c}\text { of all } \\
\text { criteria }\end{array}$ \\
\hline Goal & Indicator & Weight & Ranking & Criteria in Each Aspect & $\begin{array}{c}\text { same } \\
\text { aspect }\end{array}$ & \begin{tabular}{|c|} 
same \\
aspect
\end{tabular} & aspects & $\begin{array}{l}\text { in the } \\
\text { model }\end{array}$ \\
\hline The tour & Personal & 0.185 & 4 & $\begin{array}{c}\text { Processing a recognized } \\
\text { tour guide license }\end{array}$ & 0.417 & 1 & 0.0770 & 1 \\
\hline guide & Attributes & & & $\begin{array}{c}\text { Being experienced in } \\
\text { leading a tour }\end{array}$ & 0.209 & 3 & 0.0386 & 15 \\
\hline $\begin{array}{l}\text { selection } \\
\text { and }\end{array}$ & & & & $\begin{array}{l}\text { Processing a healthy and } \\
\text { strong body }\end{array}$ & 0.227 & 2 & 0.0418 & 14 \\
\hline Evaluation & & & & $\begin{array}{c}\text { Having no bad habits } \\
\text { such as excessive alcohol }\end{array}$ & 0.147 & 4 & 0.0270 & 18 \\
\hline \multirow[t]{4}{*}{ Model } & & & & $\begin{array}{c}\text { use, smoking and } \\
\text { chewing betel nuts }\end{array}$ & & & & \\
\hline & Professional & 0.249 & 3 & $\begin{array}{l}\text { Being familiar with } \\
\text { tourist attractions }\end{array}$ & 0.268 & 1 & 0.0668 & 4 \\
\hline & Knowledge & & & $\begin{array}{l}\text { Being conversant with } \\
\text { international etiquettes }\end{array}$ & 0.233 & 2 & 0.0580 & 9 \\
\hline & & & & $\begin{array}{l}\text { Possessing basic legal } \\
\text { knowledge }\end{array}$ & 0.188 & 4 & 0.0468 & 13 \\
\hline
\end{tabular}




\section{Conclusion}

Based on the research results, conclusions are proposed and suggestions are offered to relevant organizations and travel agencies in China with reasonable and theoretically-based guidance for the evaluation and selection of tour guides. $y$. The four aspects at the first-level of the hierarchy are: (1) personal attributes; (2) professional knowledge; (3) professional skills; (4) customer service attitude.

Based on the relative weights of the criteria in the tour guide selection and evaluation model, the top 10 important criteria are:

Processing a recognized tour guide license, being able to give explanations clearly and fluently, Handling matters,sensibly and meticulously, being familiar with tourist attractions,Possessing good skills in guiding a tour, having a prior understanding of tourists' background, being capable of handling emergencies and crises, being able to satisfy tourists' reasonable requests, being conversant with international etiquettes, possessing good communication skills.

\section{References}

[1] Saaty, T.L., 1990. The Analytic Hierarchy Process: Planning, Priority Setting, Resource Allocation. 2nd Edn., RWS Publications, Pittsburgh, ISBN-10: 0962031720, pp: 287.

[2] Spencer, L.M. and S.M. Spencer, 1993. Competence at work: Models for Superior Performance. 1st Edn., John Wiley and Sons, Inc., New York, pp: 372.

[3] Su, S.K., 2012. Use Delphi Method and AHP to construct R\&D outsourcing selection model-consumer desktop for example. MSc Thesis, National China University of Science and Technology, China.

[4] Teng, J.Y. and G.H. Tzeng, 1989a. Content characteristics and application of analytic hierarchy process (I). J. Chin. Stat. Assoc., 27: 6-22.

[5] Teng, J.Y. and G.H. Tzeng, 1989b. Content characteristics and application of analytic hierarchy process (II). J. Chin. Stat. Assoc., 27: 1-19.

[6] Wu, J.Z., 1997. A study on the development of working ability of electronic and electrical college graduates. MSc Thesis, National China Normal University, China. 